ORIGINAL ARTICLE

\title{
Osteoarthritis and meniscus disorders of the knee as occupational diseases of miners
}

\author{
G McMillan, L Nichols
}

Occup Environ Med 2005;62:567-575. doi: 10.1136/oem.2004.017137

See end of article for authors' affiliations

.....................

Correspondence to:

Dr G McMillan, Institute of

Occupational and

Environmental Medicine,

University of Birmingham,

Edgbaston, Birmingham

B15 2TT, UK; GHGM@

doctors.org.uk

Accepted

18 February 2005
Aim: To determine whether kneeling or squatting for prolonged periods is sufficiently causally associated with an increased risk of injury or degenerative disease of the knee joint as to meet the classic criteria to be considered an occupational disease of coal miners for whom these are or have been routine working postures.

Method: Systematic literature searches were made for studies relating to kneeling and squatting as part of the working environment of coal mines and the role of these postures in causation of knee disorders in coal miners, analogous occupations, populations, and communities. The working environment and potentially damaging forces on the knee when kneeling or squatting were described. Papers on the incidence or prevalence of knee disorders in occupational and other groups were scored against five criteria independently by each author, and from this a single consensus score representing the overall strength of evidence given by the research was awarded. The evidence was then weighed against the criteria for an occupational disease.

Results: Nineteen published papers were scored, the majority of which focussed on osteoarthritis as the outcome of interest. Few of the studies found focussed specifically on miners, and those that did tended to involve small numbers of subjects and were carried out before 1960, when the mining population was at its largest but epidemiological evidence of the risk factors for knee disorders was not well established. The non-mining studies in the review represent groups of workers with a similar or lesser kneeling content in their work.

Conclusion: The papers reviewed provide sufficient evidence to conclude that work involving kneeling and/or squatting is causally associated with an increased risk of osteoarthritis of the knee. In some of the more recent epidemiologically sound studies, frequent or prolonged kneeling or squatting doubles the general risk of osteoarthritis of the knees found in the general population. This may be of particular importance in welfare and medico-legal situations. There was also evidence to suggest that lifting, in combination with kneeling/squatting, an activity also performed by miners in the course of their work, is associated with an excess risk of osteoarthritis above that attributed to kneeling/squatting alone.
$\mathrm{T}$ he miner who is the victim of immediate or long term effects of an injury of the knee resulting from an accident at work commonly qualifies for compensation under the accident provisions of state or company social security provisions or private insurance. In some countries those who have developed "beat knee", defined as bursitis or subcutaneous cellulitis at or about the knee due to severe or prolonged external friction or pressure during employment in a specified occupation, also qualify for social security benefits. ${ }^{1}$ Other chronic knee disorders that cannot be related to a specific injury event are unlikely to qualify. The European Commission would like that to change and in 1990 recommended that meniscus lesions following extended periods of working in a kneeling or squatting position be included in an European Schedule of Occupational Diseases to be adopted by member nations. ${ }^{2}$ This would require, as in the United Kingdom, ${ }^{3}$ strict criteria of a work related causal relation to be defined and, perhaps, there to be evidence of a defined level of excess risk in the prescribed occupations.

When the Commission repeated its recommendation in $2003,{ }^{4}$ it was thought timely to reassess systematically the evidence base for an excess of knee disorders related to kneeling and squatting at work in general and in British coal mines in particular, as it was asserted that a significant proportion of employees had worked in seams so low that kneeling or squatting for long periods was a matter of routine.
AIM

The review was designed to determine the evidence base for the following hypotheses:

- kneeling and/or squatting for prolonged periods are causally associated with an increased risk of development or aggravation of injury or degenerative disease of the knee joint other than "beat knee";

- the excess risk is sufficiently large and specific for the defined injury or disease to be recognised as an occupational disease of coalminers.

\section{METHODS AND OUTCOME OF SEARCHES AND REVIEW}

Working to the principles of now standard best practice procedures, ${ }^{5}$ risk factors for osteoarthritis (OA) and damage to menisci and ligaments of the knees were explored with particular attention to epidemiological studies relating to coal mining and occupations or domestic activities which might place analogous strains on the knees.

The initial search was performed to see how much information specifically associated with knee injuries or disease in miners was available. The search criteria included occupational/work related postures of kneeling and/or

Abbreviations: $\mathrm{OA}$, osteoarthritis 
squatting; mining in general and coalmining in particular; nature and causation of knee injuries in general; and damage or disease of menisci, bursae, ligaments, and osteoarthritis of articular surfaces. The databases interrogated electronically were Datastar (for Medline, Toxfile, CancerLit, Embase, Biosis Previews, SciSearch, Pascal, NTIS, HSLI), Dialog (for NIOSHTic), STN (for SIGLE-System for Grey Literature in Europe), and the Internet (for COPAC and BLPC).

Two hundred and fifty five papers and reports were identified from the electronic databases whence an abstract of each was provided. Each of the authors separately read these and selected those documents which they considered related to the working environment in coal mines and/or to knee problems related to any work, sport, or leisure or in communities or populations. Both selected the same 51 papers and, additionally, one or the other selected a total of 28 further papers. These 79 papers were obtained in full text. To these were added 31 papers, reports, or other documents which met these criteria having been noted in the bibliographies of papers already obtained, offered by colleagues from archives, or, from completion of the initial electronic search to start of analysis, found through weekly online reviews of additions to PubMed, new Health and Safety Executive publications, and finally scanning the contents pages of appropriate occupational health journals as these became available.

Within these 110 papers, two systematic and seven traditional reviews were identified. To avoid bias, these papers were not read, other than to scan the bibliographies, until after the authors had drawn consensus conclusions from their own systematic review.

The remaining 101 papers were studied in full text by the two authors to determine their potential contribution, again working independently of each other to form a written view but then debating to reach a consensus when opinions differed. It was agreed that 16 of these papers had nothing relevant to contribute.

Sixteen of the remaining papers contributed to an appreciation of coalminers' working environment. Some of these and many of the others assisted in identifying and examining the risk factors for knee disorders. Finally, there were 19 published reports of studies which both authors agreed had sought causal links between knee disorders and the work of miners or analogous trades or work postures.

Working independently, following the approach used by Maetzel et al, ${ }^{6}$ each of these 19 papers was scored in the range 0 to +++ for each of five attributes of the design and conduct of the study. These marks were then reflected in a summary score to indicate the weight that should be given to the evidence presented. The attributes were representativeness, exposure ascertainment, outcome ascertainment, control of confounders, and follow up or response rate. Consensus on the summary score was then achieved between the reviewers through discussion of areas of difference in scoring.

\section{OCCUPATIONAL STRAINS AND STRESSES ON COALMINERS' KNEES \\ Kneeling, squatting, and crawling}

In the middle of the twentieth century, when some 700000 were employed in the UK coal industry, coalminers had high rates of morbidity and incapacity compared to the general population. ${ }^{7}$ As indicated in table 1, many miners won coal from seams so thin or low that they had to spend much of their days working in kneeling, crawling, or stooping postures. In the thinnest seams they worked lying down. Several papers document the working conditions and numbers of miners required to kneel in the coal industry of the 1950s and early 1960s. ${ }^{8-12}$ Kneeling and squatting
Table 1 Mechanisation of mines and working position of miners in relation to seam thickness, 1961-62*

\begin{tabular}{|c|c|c|c|c|c|}
\hline \multirow{2}{*}{$\begin{array}{l}\text { Seam } \\
\text { thickness } \\
\text { (inches) }\end{array}$} & \multirow{2}{*}{$\begin{array}{l}\text { Working } \\
\text { positiont }\end{array}$} & \multicolumn{4}{|c|}{ Degree of mechanisation (\%) } \\
\hline & & Very low & Low & Medium & High \\
\hline$<30$ & Lying & 55.7 & 18.9 & 19.1 & 6.3 \\
\hline $30-$ & Kneeling (47.9) & 24.2 & 31.1 & 22.4 & 22.2 \\
\hline $50-$ & Stooping (39.1) & 15.3 & 24.7 & 30.1 & 30.0 \\
\hline$\geqslant 70$ & Standing (5.9) & 34.4 & 25.5 & 16.5 & 23.6 \\
\hline
\end{tabular}

remained common work positions for a significant proportion of men into the 1970s and beyond. ${ }^{7}$

As it became increasingly uneconomical to mine narrow seams through the late 1980s and 1990s, the number of miners required to kneel for appreciable periods fell rapidly, and today no miner works in such conditions in the UK. By this time new groups of workers whose work required them to kneel and/or squat for long periods had developed. Perhaps the largest such group is formed by carpet fitters and floor layers who grew in numbers as fitted floor coverings became popular. These and other analogous occupations provide new potential sources of risk for long term damage to the knees. In this review, the results of appropriate studies of such trades are considered with and to complement studies of miners in order to draw conclusions on the long term effects of work in kneeling postures.

\section{Pressures in the knee joint}

In the study by Watkins et al the coalminer varied his kneeling posture according to the task in which he was engaged and according to his personal preference. ${ }^{10}$ It was observed that the stability of the knee joint could be compromised by damage or stretching of the ligaments, predisposing the joint to internal damage, ${ }^{11}$ a consequence which would be challenged today by those with experience of the management of patients with damaged or absent collateral ligaments.

Sharrard conducted experiments at the coalface to define the forces and pressures exerted upon miners' knees in the course of kneeling. ${ }^{13}$ On average a miner moved his shovel every two to five seconds, setting up a repeated cycle of immense shearing strains and loads in alternate knees. Different portions of the knee were subjected to pressures at different times. Pressure could rise suddenly over a localised area from zero to as much as $200 \mathrm{lb} /$ square inch.

\section{Slips, trips and evasive actions}

In 1957, Dr J B Atkins described the role of activities other than kneeling and crawling in the causation of internal derangements of the knee joint (a term encompassing ligament and/or meniscus damage) in miners in the South Wales coalfield. ${ }^{14}$ This evidence demonstrated the importance, as the dominant causal factor, of sudden twisting of the knee as evasive action was taken to avoid injury. Atkins recommended addressing the causes of injury by keeping roadways in good repair, not using smooth steel plates on the floor, providing boots which would give a better grip, improving lighting, and clearing obstructions at the coalface.

\section{Kneepads}

Kneepads have been in use in British mines since 1928-2915 to protect against beat knee rather than other knee disorders. ${ }^{7}$ A wider view is taken in the United States where the Mines Safety and Health Administration appears to accept that kneepads may usefully contribute to prevention 
of not only bursitis, but also damage to other structures of the unprotected knee, and it encourages use of knee pads to prevent against damage to the menisci and the ligaments. ${ }^{16}$

\section{Risk factors for common knee disorders}

The prevalence of knee pain in the general population ranges from $10 \%$ to $60 \%$ depending on age, occupation, and the definition used. ${ }^{17}$ Osteoarthritis is the most commonly attributed caus $\mathrm{e}^{18}$ but no formal diagnosis is given in many cases. ${ }^{19}$ There is a high degree of discordance between the presence of persistent knee pain and radiographic evidence of degenerative disease ${ }^{20}$ and psychological variables can greatly influence the effects of knee disorders. ${ }^{21}$

Meniscus tears are most likely to be caused by sudden rotatory or abductory strain on the semi-flexed knee joint. ${ }^{22}$ Adamson" $^{23}$ remarked "The miner works below ground in a cramped position with the knees flexed; the cartilages, therefore, are particularly liable to injury when a sudden rotatory and abductory strain is thrown on the joint with the knee in a flexed or semi-flexed position. The miner is thus particularly liable to suffer cartilage injuries." In the early 1960s, Sharrard and Liddell's study reinforced that view by showing that more coalminers than would be expected from the experience of the general population underwent menisectomy. ${ }^{11}$ At the time it was suggested that this might have been due to miners being more likely to have meniscus damage than others or, at least in part, that miners cannot work with a torn meniscus whereas this might be possible for men in other trades ${ }^{23}$ and that miners are under more pressure to have surgery to enable their return to work (however, this may not always be achieved). ${ }^{24}$

Menisectomy or meniscus injury predisposes the injured knee to the development of degenerative changes characteristic of OA. This is a common, chronic, slowly progressive, often disabling degenerative joint disorder affecting joint cartilage and subchondral bone, leading to loss of cartilage and, when extensive, to visible radiographic changes including the development of osteophytes. Such degenerative changes are irreversible. Many risk factors for OA have been identified. Those that do not or are unlikely to feature for coalminers include female gender, advanced age, ${ }^{25}$ and obesity. ${ }^{26-32}$ Those factors likely to affect them are injury (including meniscus damage and post traumatic deformity), ${ }^{172629303334}$ with up to a threefold excess over those who have not had a knee injury, and surgery. ${ }^{35-39}$ These two risk factors have been shown to be powerful influences on the development of OA. Increased physical activity and loading other than obesity are also risk factors experienced by miners. These occur during repetitive movements of the joint through kneeling, squatting, and crawling, and both sudden and persistent external loading while kneeling.

\section{Knee disorders in coalminers and analogous knee stressing trades and activities}

Nineteen reports published in the scientific literature were reviewed formally to explore the relation between knee disorders and occupation as a miner or in an analogous trade. The principal characteristics and selected results from each paper are summarised in tables 2 and 3. Table 2 summarises studies which estimate the risks of knee injury associated with kneeling and squatting. Table 3 summarises studies that estimate the prevalence of knee injury in working populations. In both of these tables the papers are listed in order of the strength of evidence they were judged to contribute. There was very little disagreement in the scoring between the two reviewers. Only five papers were given differing scores.

The earliest paper included in this review describes a case control study in the Manchester coal fields. ${ }^{40}$ The incidence of rheumatic complaints was found to be no greater in miners than in the population as a whole. The degree of incapacity (unfitness for work) was greater in miners and there was evidence of an earlier onset of symptoms as shown by a steeper rise in incidence at the fourth decade, principally due to back-hip-sciatic pain.

Kellgren and Lawrence followed this field study with a clinical and radiographic investigation of a random sample of male coal miners in their fifth decade, matched for sex and age with two control groups. ${ }^{41}$ They were careful to avoid bias in history taking, clinical examination, and reading the radiographs. Their definitions for the classification of survey radiographs are still used as the standard practice for such surveys. A positive diagnosis was made on the presence of osteophytes alone rather than coupling that finding with loss of joint space. Although this more rigorous application may have restricted cases to moderately severe and severe arthritis, it would have ignored cases of early disease and is not a serious flaw in the study design. There was a general trend in favour of an excess of OA among the miners but the differences in prevalence were not statistically significant. From this observation Kellgren and Lawrence justifiably, and cautiously, concluded that miners aged 41-50 years of age possibly suffer more OA of the knees than either manual or office workers of the same age. This was the first real evidence to support that contention.

Lawrence expanded the series of studies by comparing the knees of men employed as coalface workers and as roadway workers in the same colliery, face workers in a nearby wet mine of similar seam height, and dock workers. ${ }^{42}$ Comparing face and other underground workers was a serious flaw because, as noted in the paper, it is likely that knee pain would be a frequent cause of transfer from the face to roadways. This study's principal contribution is its demonstration of a more than twofold excess risk of definite radiographic OA of the knee in underground coal workers compared with manual workers and almost fourfold excess risk when compared with office workers, the latter difference being statistically significant.

The importance of the next paper is enhanced in terms of official appreciation, as the author was employed in the Medical Inspectorate of Mines, Ministry of Power. ${ }^{14}$ The aim of this study was to investigate the prevalence of internal derangements of the knee and the factors which might be responsible for such injuries. Although precise figures were not available for the incidence of internal derangements of the knee among miners, this disadvantage was overcome by working from admissions to rehabilitation centres to derive an estimate of minimum incidence. The rates for internal derangement of the knee in miners may be adjusted to give 180 per 100000 men-more than twice the rate in men doing heavy work in a Welsh steel works. Kneeling in narrow seams was shown to be not the only, or even the main, cause of injury-these being slipping and tripping. It seems that, rather than wear and tear causing degeneration, repeated trauma incidents account for the incidence observed in miners.

The 1962 paper by Sharrard and Liddell ${ }^{11}$ demonstrated that miners, notably face workers and especially those aged 25-54 years, appear to have an excess incidence of meniscus damage of up to 5:1 over the general population. Although cartilage tears were most common in those who knelt at work, the evidence showed that the injury might actually occur when a man is more active or undertakes sudden movements on the knee. Laxity of the knee joint was linked to kneeling at work, thus increasing the susceptibility of the knee to rotatory injuries and consequent damage of the menisci. This study is flawed only by the possible bias of miners, driven by the fitness requirements of their work, seeking hospital treatment at an earlier stage than other men. 
Table 2 Characteristics and selected results of studies examining occupational kneeling and risk of knee injury (males only)

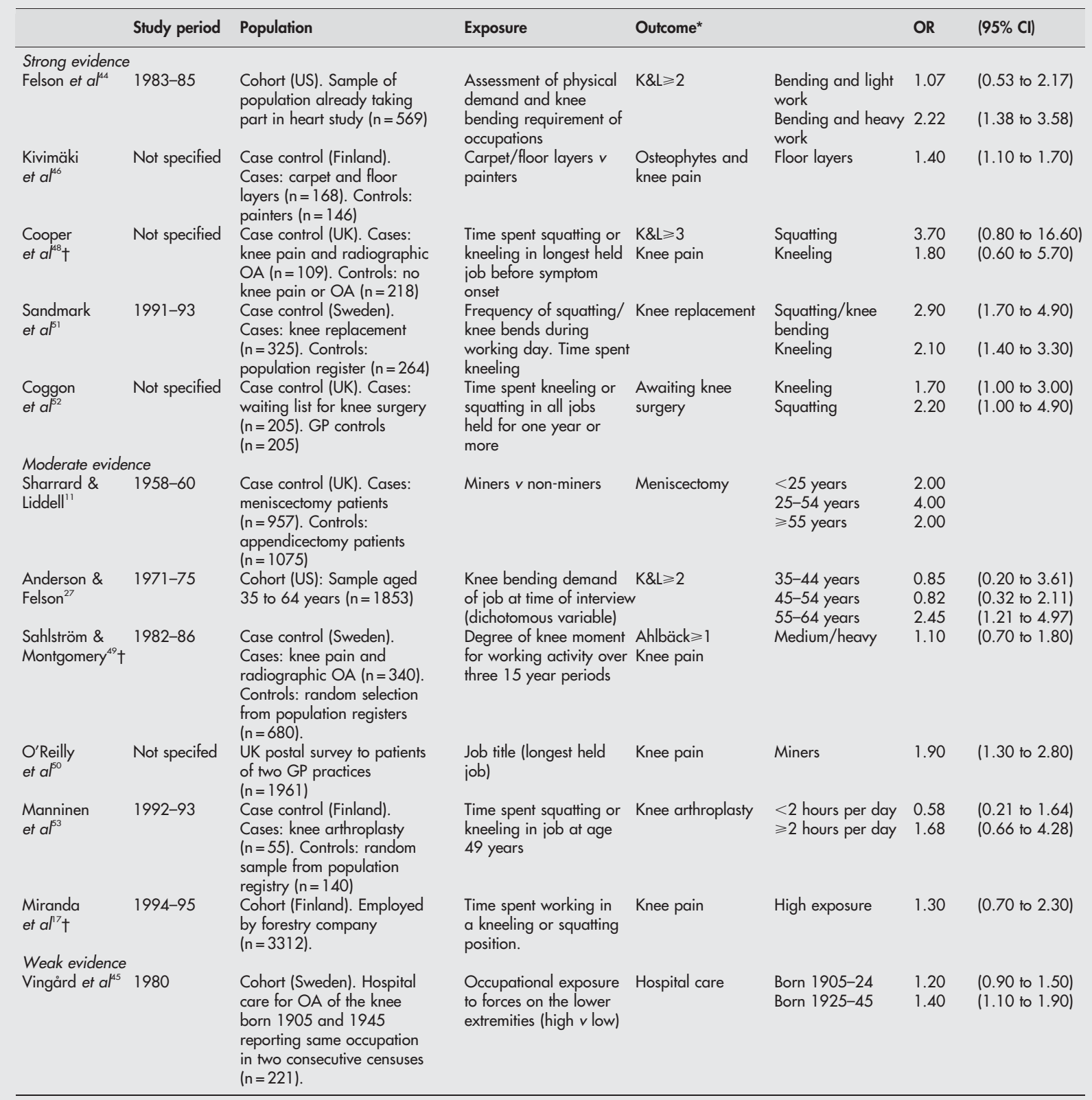

${ }^{*} \mathrm{~K} \& \mathrm{~L}$ and Ahlbäck refer to classifications of radiographic appearance of arthrosis of the knee.

†Results given are for male and female subjects combined.

This paper appears to have been the last one focussed solely on miners to be published in the literature in English. The next paper relevant to occupational strains on the knees was a study by Lindberg and Montgomery ${ }^{43}$ who used an archive of existing radiographs to demonstrate that the prevalence and severity of definite OA of the knee was significantly greater in those who had done heavy work over tens of years.

There then followed a number of papers derived from large scale United States population studies originally designed for other purposes and extended to incorporate OA of the knees. Although these provide much valuable information about that disease and some about attributes of occupations linked to prevalence and severity, relatively little can be attributed to specific occupations. The first of these papers was published in 1988 by Anderson and Felson who studied factors associated with OA of the knee in the First National Health and Nutrition Examination Survey (HANES I) population. ${ }^{27}$ The physical demands of respondents' jobs were assessed using a published national standard. Using this method rather than individual questioning is a weakness. The authors remarked that they might have underestimated attributable risk by failing to include those who had retired or switched jobs because of OA (the healthy worker effect). After controlling for confounders, there was a strong association between knee OA and physically demanding occupations in those aged 55-64 years.

Felson and co-workers later used the Framingham Heart Study in a longitudinal assessment of occupational joint use and $\mathrm{OA}$ in a large cohort. ${ }^{44}$ They found that occupations which combined knee bending and physical demands were significantly related to and may be an important cause of radiographic OA.

In 1991 Vingård and colleagues published a report of a register based cohort study of the relation between occupation and OA of the hip and knee. ${ }^{45}$ Exposure was not ascertained from the individual but from an occupational 


\begin{tabular}{|c|c|c|c|c|c|c|}
\hline & Study period & Population & Exposure & Outcome* & & Prevalence \\
\hline $\begin{array}{l}\text { Strong evidence } \\
\text { Lawrence \& Aitken- } \\
\text { Swan }{ }^{40}\end{array}$ & $1945-49$ & $\begin{array}{l}\text { Case control (UK). Cases: miners } \\
(\mathrm{n}=1742) \text {. Controls: non-miners } \\
\text { from engineering yard, offices, } \\
\text { mining families and the local } \\
\text { population ( } \mathrm{n}=1931 \text { ) }\end{array}$ & Miners $v$ non-miners & $\begin{array}{l}\text { Rheumatic pain } \\
\text { in the knee }\end{array}$ & $\begin{array}{l}\text { Miners } \\
\text { Non-miners }\end{array}$ & $\begin{array}{l}4.9 \% \\
2.5 \%\end{array}$ \\
\hline Atkins $^{1 / 4}$ & 1953 & $\begin{array}{l}\text { Cohort (UK). Mine employees } \\
\text { with damage to a knee cartilage }\end{array}$ & Employment in mine & Meniscus damage & $\begin{array}{l}\text { Kneeling } \\
\text { Fall of coal } \\
\text { Tripping } \\
\text { Other }\end{array}$ & $\begin{array}{l}10.4 \% \\
20.0 \% \\
45.2 \% \\
24.3 \%\end{array}$ \\
\hline $\begin{array}{l}\text { Moderate evidence } \\
\text { Kellgren \& Lawrence }\end{array}$ & Not specified & $\begin{array}{l}\text { Case control (UK). Cases: } \\
\text { miners }(n=84) \text {. Controls: } \\
\text { manual }(n=45) \text { and office } \\
\text { workers }(n=42)\end{array}$ & $\begin{array}{l}\text { Miners } v \text { manual } v \text { office } \\
\text { workers }\end{array}$ & $\begin{array}{l}\text { Radiograph } \\
\text { assessed on five } \\
\text { point scale of } \\
\text { severity }\end{array}$ & $\begin{array}{l}\text { Miners } \\
\text { Manual } \\
\text { Office }\end{array}$ & $\begin{array}{l}6.0 \% \\
2.0 \% \\
0 \%\end{array}$ \\
\hline Jensen et $a^{\mu 7}$ & Not specified & $\begin{array}{l}\text { Case control (Denmark). Cases: } \\
\text { floorlayers }(n=50) \text {. Controls: } \\
\text { carpenters }(n=51) \text { and } \\
\text { compositors }(n=49)\end{array}$ & $\begin{array}{l}\text { Floorlayers } v \text { carpenters } v \\
\text { compositors }\end{array}$ & $K \& L \geq 2$ & $\begin{array}{l}\text { Floorlayers } \\
<50 \text { years } \\
\geqslant 50 \text { years } \\
\text { Carpenters } \\
<50 \text { years } \\
\geqslant 50 \text { years } \\
\text { Compositors } \\
<50 \text { years } \\
\geqslant 50 \text { years }\end{array}$ & $\begin{array}{l}0 \% \\
34.0 \% \\
7.0 \% \\
9.0 \% \\
\\
5.0 \% \\
9.0 \%\end{array}$ \\
\hline $\begin{array}{l}\text { Weak evidence } \\
\text { Lawrence }^{42}\end{array}$ & Not specified & $\begin{array}{l}\text { Case-control (UK). Cases: } \\
\text { miners }(n=221) \text {. Controls: } \\
\text { dockers }(n=54 \text { ) and light } \\
\text { manual/office staff }(n=87)\end{array}$ & $\begin{array}{l}\text { Miners } v \text { dockers } v \text { light } \\
\text { manual/office workers } \\
\text { with definite radiographic } \\
\text { changes }\end{array}$ & $\begin{array}{l}\text { Radiograph } \\
\text { assessed on five } \\
\text { point scale of } \\
\text { severity }\end{array}$ & $\begin{array}{l}\text { Miners } \\
\text { Dockers } \\
\text { Light manual/ } \\
\text { office workers }\end{array}$ & $\begin{array}{l}24.8 \% \\
11.0 \% \\
9.2 \%\end{array}$ \\
\hline $\begin{array}{l}\text { Lindberg \& } \\
\text { Montgomery }\end{array}$ & Not specified & $\begin{array}{l}\text { Case control (Sweden). Cases: } \\
\text { shipyard workers }(n=332) \text {. } \\
\text { Controls: teachers/office staff } \\
(n=352) \text { and population } \\
\text { controls }(n=438)\end{array}$ & $\begin{array}{l}\text { Shipyard workers } v \\
\text { teachers/office staff } v \\
\text { population controls } \\
\text { (occupation unknown) }\end{array}$ & $\begin{array}{l}\text { Ahlback } \\
\text { (where available) }\end{array}$ & $\begin{array}{l}\text { Shipyard workers } \\
\text { Teachers/office } \\
\text { staff } \\
\text { Population controls }\end{array}$ & $\begin{array}{l}3.9 \% \\
1.4 \% \\
1.6 \%\end{array}$ \\
\hline
\end{tabular}

physician's interpretation of records. Outcome definition was from discharge records rather than radiographs or other more clearly defined source operating to an auditable standard. Although there was a classification for miners and quarrymen, the numbers of workers in this group were insufficient to carry out a specific analysis.

Next to be published was a study of knee disorders in carpet and floor layers compared with age matched painters. ${ }^{46}$ Radiography and exposure assessment were unusually thorough in this study. Working practices were videoed and assessed for kneeling in a sample of participants. This is probably a better way of assessing work than relying on individual recall or opinion. Carpet and floor layers participated in the examinations more frequently than the painters, perhaps because workers with knee pain were more willing to be examined. Information from non-attendees showed that most were not experiencing knee problems and considered the examination unnecessary. Conversely, the actual effect of kneeling for much of the working day may actually be higher than reported, as primary and secondary selection would dilute the occupational load and thus the observed rates of OA in those who have to kneel at work. Higher load requirements in a job tend to select out men with knee disorders from employment. Restricting the study to those less than 50 years of age to diminish the effect of possible secondary selection due to knee disorders was a prudent decision. Overall this study indicates that kneeling work increases the risk of acute bursitis and of chronic degeneration, but does not carry an increased risk of meniscus and ligament injuries.

A second study also focussed on carpet and floor layers. ${ }^{47}$ The control groups-carpenters and compositors-were well chosen for different amounts of knee straining work. Although some might consider that it may have been better to concentrate on grade $3 \mathrm{OA}$ and over, the method used is thought to be satisfactory, although the radiographs were not weight bearing. There was a sound, well disciplined reading regime for the radiographs and good agreement between readers. The differences in prevalence of $\mathrm{OA}$ in the three groups were not statistically significant. For those aged 50 years and above, the differences in prevalence of OA and knee complaints over the previous 12 months was statistically significant between trade groups. Assuming they have the same annual dose of wear and tear from floor laying, the differences in prevalence between young and older subjects appear to demonstrate a time dose response. Overall, the study provides more evidence to suggest that work in which a considerable amount of time is spent weight bearing on the knees may be a risk factor for the development of OA above the age of 50 years.

Returning to the order of publication, the next two papers are by Cooper and colleagues and were published in 1994..$^{33} 48$ They describe a well designed, population based case control study to determine the profile of several putative risk factors for OA of the knee. Occupational activity is discussed in the second paper. ${ }^{48}$ Adjusting for obesity and Heberden's nodes, the odds ratio (OR) for kneeling and for squatting, calculated separately, were statistically significant. When the OR are calculated for kneeling adjusting for squatting, and vice versa, then the OR for each is reduced, remaining increased but not significantly. Subjects who regularly lifted over $25 \mathrm{~kg}$ at work in addition to kneeling or squatting were found to be more than five times as likely to have knee OA than subjects who did neither activity; however, this analysis is based on small numbers of subjects. Unfortunately the number of male cases is small $(\mathrm{n}=30)$. It is unfortunate for studies of miners, who form an all male group in the UK, that the rates for men and women are combined. In summary, these studies add 
Table 4 Evidence for and against an increased risk of meniscus damage and osteoarthritis of the knee in miners and analogous trades

\begin{tabular}{|c|c|c|c|c|c|}
\hline \multirow{5}{*}{$\begin{array}{l}\text { Lawrence \& Aitken-Swan }^{40} \\
\text { Kellgren \& Lawrence } \\
\text { Lawrence }^{42}\end{array}$} & \multirow{4}{*}{$\begin{array}{l}\text { Study period } \\
1945-49 \\
\text { Not specified }\end{array}$} & \multicolumn{2}{|c|}{ Meniscus injury risk increased* } & \multicolumn{2}{|c|}{ Knee OA risk increased* } \\
\hline & & Yes & No & Yes & No \\
\hline & & & & +++ & \\
\hline & & & & ++ & \\
\hline & Not specified & & & ++ & \\
\hline Atkins $^{14}$ & 1953 & +++ & & & \\
\hline Sharrard \& Liddell" & $1958-60$ & ++ & & & \\
\hline Lindberg \& Montgomery ${ }^{43}$ & Not specified & & & ++ & \\
\hline Anderson \& Felson ${ }^{27}$ & $1971-75$ & & & ++ & \\
\hline Felson et $a^{44}$ & $1983-85$ & & & +++ & \\
\hline Vingård et $a l^{\mu 5}$ & 1980 & & & + & \\
\hline Kivimäki et $\left.a\right|^{46}$ & Not specified & & +++ & +++ & \\
\hline Cooper et $a \beta^{\beta 3}$ & Not specified & & & ++ & \\
\hline Cooper et $a^{48}$ & Not specified & & & +++ & \\
\hline Sahlström \& Montgomery ${ }^{49}$ & $1982-86$ & & ++ & & ++ \\
\hline Jensen et $\left.a\right|^{47}$ & Not specified & & & ++ & \\
\hline $\mathrm{O}^{\prime}$ Reilly et $a^{50}$ & Not specified & & & ++ & \\
\hline Sandmark ef $a^{51}$ & 1991-93 & & & +++ & \\
\hline Coggon et $a P^{52}$ & Not specified & & & +++ & \\
\hline Miranda et al $l^{77}$ & 1994-95 & & & & + \\
\hline Manninen et $a P^{53}$ & $1992-93$ & & & ++ & \\
\hline
\end{tabular}

significantly to the view that injury, menisectomy, and kneeling-with or without lifting weights—are important risk factors for knee OA.

Radiographs for knee disorders of the people of Malmo were assessed in a study by Sahlström and Montgomery. ${ }^{49}$ The relative risk (RR) of knee arthrosis was slightly increased in subjects who reported loading of the knee joint when bending. Once this estimate was corrected for confounders, it appeared that work that induces weight bearing knee bending by itself does not significantly increase the risk of arthrosis.

In 2000, O'Reilly et al ${ }^{50}$ conducted a study to examine the relation between knee pain and occupation in a random sample from two UK GP practices. The screening question was a little ambiguous about the frequency of pain needed to qualify. Although symptoms rather than radiographic changes drive people to seek treatment or stop work, symptoms are difficult to verify and do not sit well alone as evidence for an occupational disease. Increased odds for pain were apparent in carpenters, miners, and construction workers-all being occupations that are likely to involve bending and lifting. The finding in miners is based on 148 males citing mining as their longest held job.

Among several studies published in 2000, Sandmark and colleagues $^{51}$ carried out a population based case referent study investigating the effect of lifelong physical load on the development of knee OA leading to prosthetic surgery. The absence of $\mathrm{OA}$ in the controls was taken on the basis of questioning by telephone interview and questionnaire, a possible weakness alleviated by the use of trained interviewers. There was good control of confounders by age matching and exclusion of secondary causes of OA. Among males there were highly significant associations with high exposure to squatting or knee bending and high exposure to kneeling, both with a dose response association.

Coggon et $a l^{52}$ conducted a case control study of patients listed for surgical treatment of knee OA to assess the risk associated with kneeling, squatting, and other occupational activities. There can be little doubt that the cases had severe $\mathrm{OA}$ as they were on the waiting list for surgery. Controls with OA were excluded from the survey only if they were on the list for knee surgery, an assumption that may be unsound. The demand for knee replacement is likely to be influenced by handicap which, in turn, is determined by the individual's needs for a rewarding life, which might include the need for employment. However, as the majority of cases were beyond retirement age at the time of listing for surgery, any bias is likely to be small. Healthy worker effect was taken into account in analysis of work history for jobs held 10 years before. Osteoarthritis was more common in people who reported prolonged kneeling or repeatedly rising from a squatting position. Combined kneeling and squatting carried an excess risk that was statistically significant. The risk was particularly high in men who reported lifting and kneeling in the course of their work. No clear exposure-response relation was apparent for any of the activities.

The next study was published in $2002^{17}$ and used a comprehensive questionnaire to investigate knee pain in employees of a Finnish forestry company. Working with the trunk forward flexed in a kneeling or standing position, daily lifting and physically strenuous work increased the risk of knee pain significantly. Working in a kneeling or squatting position did not appear to be a significant predictor of knee pain. Loss to follow up is a concern as the healthy worker effect could be present.

The final study reviewed was a case referent study of the impact of physical workload on the risk of severe knee OA leading to knee arthroplasty in Finland. ${ }^{53}$ An increased RR was found for a high physical workload and with kneeling for two or more hours a day; however, neither relation was statistically significant.

\section{CONCLUSIONS}

Few of the studies that have been reviewed focus specifically on miners as an occupational group. Those that do concentrate on miners tend to involve small numbers of study subjects and were carried out in 1950s and 60s when epidemiological evidence of the risk factors for OA was not well established. It is unfortunate that large scale epidemiological studies were not carried out by the industry at that time, prompted by the apparent excess risks reported in the literature and other reports. The quality of studies has increased steadily over the decades and is now at a high level. It is considered that enough have been reviewed to allow an informed evidence based conclusion to be drawn on lesions of the ligaments and menisci and on OA of the knee joint.

The score attached to each paper indicates the weight that may be given to the evidence it provides. As an aid to drawing conclusions in a disciplined way, the number of + marks for 
and against the propositions that work as a miner or in analogous trades or activities increases the risk of knee disorders are shown in table 4. This is not a quantitative exercise (so there are no totals), but it should be used as a visual aid to the strength and consistency of the accumulated evidence. From this it can be concluded that there is strong and generally consistent evidence from well conducted epidemiological studies, based on established methodology, to conclude that work involving kneeling and/or squatting is associated with an increased risk of OA of the knees. This evidence has been maintained and strengthened over the years. The pattern of evidence for damage to the menisci has changed through time. Clearly this was a serious problem up to the 1960s but the evidence suggests that it has been resolved. These injuries are of particular biological significance as they predispose to the development of OA.

There is also evidence in the medical literature that, before and perhaps in and beyond the 1970s, underground workers in mines spent a significant proportion of time in a kneeling or squatting posture. Post 1970, the proportion of time spent kneeling or squatting reduced with increasing mechanisation. During their work miners are also required to lift substantial weights $(>25 \mathrm{~kg})$ while in a kneeling or squatting position. There is evidence from several of the epidemiological studies reviewed to suggest that lifting, in combination with kneeling/squatting, is associated with an excess risk of OA above that attributed to kneeling/squatting alone. Thus there were hazards that relate to the disorder and the exposure preceded the appearance of that disorder. The temporality required for proof of a causal relation criterion is met.

Proof of specificity strengthens proof of a causal relation. This presents a problem as only the apparent earlier age of onset of the pathology seen in miners sets it apart from the knee disorders seen in other working men.

Demonstration of dose-response is another required criterion that poses a problem in both meniscus damage and OA. The former is usually an acute event; the latter becomes increasingly common with age in the general population. No evidence has been found which allows separation of age from time employed as a miner-it is possible that the two run so closely together that they are inseparable.

Plausibility and coherence of the relation present no problems. It would be much less plausible for no damage to be done given the stresses the lower limbs endure during work at a coalface. The development of the disorders described in the studies seems to be perfectly in line with what is known of their natural history.

Little animal experimental evidence is available. There have been no prospective trials following groups of men which include a substantial proportion of miners over years to determine what happens to their knees. What animal evidence has been studied during the review indicates that the articular cartilage of the knee joint is susceptible to damage if placed under sustained pressure. Studies of pressures on the knee during coalface work have demonstrated that these are substantial.

Most of the evidence presented is based on analogous work activities rather than studies of miners. Analogy of exposure through domestic or commercial exposures to kneeling, squatting, or knee bending forms an important part of the evidence of a causal relation between knee disorders and the work done by coalminers.

Overall, the accumulated evidence meets the criteria sufficiently to conclude that there is a causal relation between aspects of work as a coalminer and the development of OA of the knee joint and, perhaps only in the past, damage to the menisci and ligaments. Prolonged kneeling and squatting may predispose the coalminer's knees to suffer damage to the menisci when he slips, trips, or seeks to avoid falling objects and so forcibly rotates the knee joint. It is, however, these events rather than kneeling and squatting that appear to be most associated with the increased risk. Persistent prolonged kneeling, squatting, and repeated knee bending are associated with an increased risk of OA, and that risk is increased in combination with heavy lifting.

It is more difficult to draw conclusions as to whether prescription as an occupational disease for purposes of state or other compensation or social benefit schemes is merited. For that purpose it has been assumed that a disease may be prescribed only if there is a recognised risk to workers exposed to a particular substance or occupational activity and when the link between the disease and the occupation can be reasonably presumed and established in individual cases. In diseases which occur in the general population there may be no difference in the pathology or clinical presentation to distinguish an occupational from a non-occupational cause. In these circumstances, in order to recommend prescription, authorities may seek evidence of a particular level of excess risk in the occupational group, perhaps that the incidence is double that of unexposed groups-as is the custom in the UK.

There is nothing to distinguish the knee disorders of miners from those found in the general population. There is, however, evidence of a statistically significant excess risk in miners and other men undertaking work involving kneeling and knee bending. That excess amounts to a doubling of the risk in some, but not all, of the better more recent studies.

\section{CURRENT CONCLUSIONS AND PREVIOUS REVIEWS}

It can be useful to assess how the conclusions in a new review fit with those drawn by others. Felson' $\mathrm{s}^{54}$ overview of the epidemiology of hip and knee OA concluded that repetitive physical occupational activity appeared to be a major risk factor for knee OA. By 1987 there was more evidence from the Framingham Osteoarthritis Study and it appeared that knee injury and occupational knee bending and physical labour were risk factors. ${ }^{25}$ Writing in 1991, Peyron $^{55}$ seemed convinced that overuse of normal joints was associated with an increase in the incidence of $\mathrm{OA}$ in the knees and advised modifying working conditions. In the same year Hochberg published a review looking at current concepts and new insights to the epidemiology of OA. ${ }^{56}$ The attention in this review focussed on prospective epidemiological studies including three USA community studies and concluded that subjects with knee OA are more likely to have held jobs with greater knee bending and strength demands. Revisiting the topic in a 1994 review, Felson ${ }^{57}$ states: "Multiple studies of individual occupations and of populations have suggested that occupation-related joint overuse is an important cause of knee, hip and other joint OA. Occupational physical activities over many years can induce OA in selected joints. Well-studied examples include evidence of OA in the knees and spine of miners." The following year, Cooper $^{58}$ stated "There is now clear epidemiological evidence that occupational activity is a contributor to the risk of osteoarthritis at the hip and knee ... For the knee, evidence suggests that repetitive knee use, perhaps coupled with heavy lifting, is the principal biomechanical factor."

It is thought that Jensen and Eenberg ${ }^{59}$ were the first to apply systematic review techniques to knee OA. Summarising the results, they stated that all the studies reviewed demonstrated a significantly increased prevalence of knee OA for subjects with kneeling or squatting work and four showed this relation with heavy physical work. Occupational exposure could not be sufficiently documented as the cause of meniscus lesions. Maetzel and colleagues ${ }^{6}$ systemically $^{2}$ 
reviewed nine papers, all included in this review, and scored by the system used here. They concluded that, in men, a consistent positive relation exists between work involving knee bending and knee OA, with an OR of approximately two. In 2000, Palmer and Cooper, investigating the effect of repeated movements and trauma on the musculoskeletal system, found the most compelling evidence linking knee OA came from the HANES and the Framingham studies. ${ }^{60}$

In overall conclusion, the review papers published have moved over time towards conclusions similar to those of this review. Little has been said recently about meniscus and ligament injuries in reviews but the 1950s and 60s papers remain convincing. There is evidence that coalminers have long had an excess risk of meniscus lesions and that those who have routinely had to kneel or squat and lift heavy weights in these positions have been placed at excess risk of developing OA of the knee joint.

\section{ACKNOWLEDGEMENTS}

We are grateful to the Union of Democratic Mineworkers for the funding of this work and also for their help in explaining mining terms. We would also like to acknowledge the valuable assistance of the Information Science staff at the MRC Institute of Environmental Health, Leicester for their work with electronic searches and the Secretariat of IIAC, the Institute of Directors' Information Services, the Institute of Occupational Safety and Health, and the Faculty of Occupational Medicine for their help in locating information sources.

\section{Authors' affiliations}

G McMillan, L Nichols, Institute of Occupational and Environmental Medicine, University of Birmingham, Edgbaston, Birmingham, UK

Declaration of interests: This review was funded by the Union of Democratic Mineworkers (UDM) under a contract with the University of Birmingham that ensured the independence of the investigators, the integrity of the work and the right to publish the results without prior approval.

\section{REFERENCES}

1 Social Security (Industrial Injuries) (Prescribed Diseases) Regulations 1985 (SI 1985 No. 967) with amendments in SI 1987/335, SI 1987/2112, SI 1989/ 1207, and SI 1993/862.

2 Commission of the European Communities Recommendation 90/326/ECC of 22 May 1990 concerning the European schedule of occupational diseases.

3 Department of Social Security. Social Security Administration Act 1992. Disorders of the Knee. Cm 2842, 1995. London: HMSO, May, 1995.

4 Commission of the European Communities C (2003) 3297 final Commission Recommendation of 19/09/2003 concerning the European schedule of occupational diseases.

5 Undertaking Systemic Reviews of Research on Effectiveness. CRD Report Number 4 (second edition). NHS Centre for Reviews and Dissemination, University of York, March, 2001.

6 Maetzel A, Mäkelä M, Hawker G, et al. Osteoarthritis of the hip and knee and mechanical occupational exposure-a systemic overview of the evidence. J Rheumatol 1997;24:1599-607.

7 Liddell FDK. Morbidity of British coal miners in 1961-62. Brit J Ind Med 1973;30:1-14

8 Fisher SW. Medical hazards in coal mining. Trans Assoc of Ind Med Off 1953;2:52-8.

9 Roantree WB. A review of 102 cases of beat conditions of the knee. Br J Ind Med 1957; 14:253-7.

10 Watkins JT, Hunt TA, Fernandez RHP, et al. A clinical study of beat knee. $\mathrm{Br} J$ Ind Med 1958;15:105-9.

11 Sharrard WJW, Liddell FDK. Injuries to the semilunar cartilages of the knee in miners. Br J Ind Med 1962;19:195-202.

12 Sharrard WJW. Aetiology and pathology of beat knee. Br J Ind Med 1963;20:24-31.

13 Sharrard WJW. Pressure effects on the knee in kneeling miners. Ann R Coll Surg Engl 1965;36:309-24.

14 Atkins JB. Internal derangement of the knee joint in miners. Br J Ind Med 1957;14:121-6.

15 Douglas CG, Gibb G. Report of the Departmental Committee on the Use of the Guss in Somerset Mines. Mines Department Guss Committee. 1928-29, Cmd 3200, London: HMSO).

16 MSHA. www.msha.gov/illness_Prevention/ideas/kneepad.htm.

17 Miranda H, Viikari-Juntura E, Martikainen R, et al. A prospective study on knee pain and its risk factors. Osteoarthritis Cartilage 2002; 10:623-30.
18 Andersen RE, Crespo CJ, Ling SM, et al. Prevalence of significant knee pain in older Americans: results from the third National Health and Nutrition Examination Survey. J Am Geriatr Soc 1999;47:1435-8.

19 Anderson JAD. Arthrosis and its relation to work. Scand J Work Environ Health 1984; 10:429-33.

20 Hannan MT, Felson DT, Pincus T. Analysis of the discordance between radiographic changes and knee pain in osteoarthritis of the knee. J Rheumatol 2000:27:1513-17

21 Salaffi F, Cavalieri F, Nolli M, et al. Analysis of disability in knee osteoarthritis. Relationship with age and psychological variables but not with radiographic score. J Rheumatol 1991;18:1581-6.

22 Smillie IS. In: Injuries of the knee joint, 5th edn. Edinburgh: Churchill Livingston, 1978.

23 Adamson WAD. Injuries of the cartilage in miners. Edinburgh Med $J$ 1946;53:37-43.

24 Want E. Letter: Partial meniscectomy preferred. BMJ 1978;1:1417.

25 Felson DT, Naimark A, Anderson L, et al. The prevalence of knee osteoarthritis in the elderly. The Framingham Osteoarthritis Study. Arthritis Rheum 1987;30:914-18.

26 Felson DT. The Epidemiology of Knee Osteoarthritis. Results from the Framingham Osteoarthritis Study. Semin Arthritis Rheum 1990;20(3)(Suppl 1):42-50.

27 Anderson JJ, Felson DT. Factors associated with osteoarthritis of the knee in the first national Health and nutritional examination survey (HANES). Evidence for an association with overweight, race and physical demands of work. Am J Epidemiol 1988;128:179-89.

28 van Saase JLCM, Vandenbroucke JP, van Romunde LKJ, et al. Osteoarthritis and obesity in the general population: a relationship calling for an explanation. J Rheumatol 1988;15:1152-8.

29 Davis MA, Ettinger WH, Neuhaus JM, et al. The association of knee injury and obesity with unilateral and bilateral osteoarthritis of the knee. Am J Epidemiol 1989; 130:278-88.

30 Kohatsu ND, Schurman DJ. Risk factors for the development of osteoarthritis of the knee. Clin Orthop 1990;261:242-6.

31 Felson DT, Zhang Y, Anthony JM, et al. Weight loss reduces the risk for symptomatic knee osteoarthritis in women. The Framingham study. Ann Intern Med 1992;116:535-9.

32 Huang $\mathrm{MH}$, Chen $\mathrm{CH}$, Chen TW, et al. The effects of weight reduction on the rehabilitation of patients with knee osteoarthritis and obesity. Arthritis Care Res 2000;13:398-405.

33 Cooper C, McAlindon T, Snow S, et al. Mechanical and constitutional risk factors for symptomatic knee osteoarthritis: differences between medial tibiofemoral and patellofemoral disease. J Rheumatol 1994;21:307-13.

34 Wickström G, Hänninen K, Mattsson T, et al. Knee degeneration in concrete reinforcement workers. $\mathrm{Br} J$ Ind Med 1983;40:216-19.

35 Fairbank TJ. Knee joint changes after meniscectomy. J Bone Joint Surg (Br) 1948;30:664-70.

36 Jackson JP. Degenerative changes in the knee after menisectomy. BMJ 1968;2:525-7.

37 Appel H. Late results after menisectomy in the knee joint: a clinical and roentgenologic follow-up investigation. Acta Orthop Scand 1970;(suppl 133):6-109.

38 Allen PR, Denham RA. Late degenerative changes after menisectomy. Factors affecting the knee after operation. J Bone Joint Surg 1974;66B:666-71.

39 Johnson RJ. Factors affecting late results after menisectomy. J Bone Joint Surg 1974:56A:719-28.

40 Lawrence JS, Aitken-Swan J. Rheumatism in miners. Part 1: Rheumatic complaints. Br J Ind Med 1952;9:1-18.

41 Kellgren JH, Lawrence JS. Rheumatism in miners. Part II. X-ray study. Br J Ind Med 1952:9:197-207.

42 Lawrence JS. Rheumatism in miners. Part III Occupational factors. Br J Ind Med 1955;12:249-61.

43 Lindberg H, Montgomery F. Heavy labour and the occurrence of gonarthrosis. Clin Orthop 1987;214:235-6.

44 Felson DT, Hannan MT, Naimark A, et al. Occupational physical demands, knee bending and knee osteoarthritis: Results from the Framingham Study. $J$ Rheumatol 1991; 18:1587-92.

45 Vingård E, Alfredsson L, Goldie I, et al. Occupation and osteoarthrosis of the hip and knee: a register based cohort study. Int J Epidemiol 1991;20:1025-31.

46 Kivimäki J, Riihimäki, Hänninen K. Knee disorders in carpet and floor layers and painters. Scand J Work Environ Health 1992;18:310-16.

47 Jensen LK, Mikkelsen S, Loff IP, et al. Radiographic knee osteoarthritis in floorlayers and carpenters. Scand J Work Environ Health 2000;26:257-62

48 Cooper C, McAlindon T, Coggon D, et al. Occupational activity and osteoarthritis of the knee. Ann Rheum Dis 1994;53:90-3.

49 Sahlström A, Montgomery F. Risk analysis of occupational factors influencing the development of arthrosis of the knee. Eur J Epidemio 1997; 13:675-9.

50 O'Reilly SC, Muir KR, Doherty N. Occupation and knee pain: a community study. Osteoarthritis Cartilage 2000;8:78-81.

51 Sandmark H, Hogstedt C, Vingård E. Primary osteoarthrosis of the knee in men and women as a result of lifelong physical load from work. Scand J Work Environ Health 2000;26:20-5

52 Coggon D, Croft P, Kellingray S, et al. Occupational physical activities and osteoarthritis of the knee. Arthritis Rheum 2000;43:1443-9.

53 Manninen $\mathbf{P}$, Heliövaara $M$, Riihimäki $\mathrm{H}$, et al. Physical workload and the risk of severe knee osteoarthritis. Scand J Work Environ Health 2002;28:25-32.

54 Felson DT. Epidemiology of hip and knee osteoarthritis. Epidemiol Rev $1988 \cdot 10: 1-28$ 
55 Peyron JG. Is osteoarthritis a preventable disease? J Rheumatol 1991; 18(Suppl 27):2-3.

56 Hochberg MC. Epidemiology of osteoarthritis: current concepts and new insights. J Rheumatol 1991;18(Suppl 27): 4-6.

57 Felson DT. Do occupation-related physical factors contribute to arthritis? Baillieres Clin Rheumatol 1994;8:63-77.
58 Cooper C. Occupational activity and the risk of osteoarthritis. J Rheumatol 1995;22(Suppl 43):10-12.

59 Jensen LK, Eenberg W. Occupation as a risk factor for knee disorders. Scand J Work Environ Health 1996;22:165-75.

60 Palmer K, Cooper C. Repeated movements and repeated trauma affecting the musculoskeletal system. In: Hunter's Disease of Occupations, 9th edn. London: Arnold, 2000.

$\mathrm{ECHO}$

\section{Physical sports curtail sick leave}

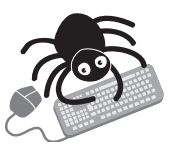

Please visit the Occupational and

Environmental Medicine website [www. occenvmed. com] for a link to the full text of this article. $\longrightarrow$ ompanies would benefit by encouraging employees to take part in physical sports, reducing sick leave, according to a prospective study. Physically demanding sports lowered sickness absence among workers in industrial, administrative, and service sectors and especially those in sedentary jobs, the cohort study in the Netherlands has confirmed.

For workers with sedentary jobs risk of absence was less if they had engaged in sport, though not frequently, compared with never doing sport, after adjustment for age, sex, alcohol intake, and smoking. They also had a better chance of recovery-within five daysbut clocked up a higher proportion of short absences.

Mean duration of sick leave was significantly lower and about 20 days less at baseline for workers who practised sport compared with those who did not or those who had never done so in their lifetime. The largest differences occurred in jobs with a large sedentary component, at 25 and 50 days less, respectively.

The data form part of the study on musculoskeletal disorders, absenteeism, stress, and health (SMASH) determining work risk factors for musculoskeletal injuries to the lower back, neck, and shoulder. This study compared sickness absences in over 1700 men and women aged 18-59 years working for 24 hours minimum a week for at least a year in 24 companies. Data on work and sporting activities were collected from questionnaires at baseline and yearly for three years and on sick leave from company records.

The study confirms other studies, most of which are cross sectional or interventional. A Van den Heuvel SG, et al. British Journal of Sports Medicine 2005;39:e15 (http://www.bjsportmed.com/cgi/content/ full/39/1/e15). 